\title{
OUR EXPERIENCE WITH DIAGNOSTICS OF CONGENITAL DISORDERS OF GLYCOSYLATION
}

\author{
Albahri Ziad ${ }^{1}$, Marklová Eliška ${ }^{1}$, Vaníček Hubert ${ }^{1}$, Minxová Lenka ${ }^{1}$, Dědek Petr ${ }^{1}$, Skálová Sylva ${ }^{1}$, Talábová Marika ${ }^{2}$, \\ Vávrová Jaroslava ${ }^{3}$ and Rencová Eva ${ }^{4}$
}

Charles University in Prague, Faculty of Medicine in Hradec Králové, Czech Republic: Department of Paediatrics ${ }^{1}$, Department of Neurology ${ }^{2}$, Department of Clinical Chemistry ${ }^{3}$, Department of Ophthalmology ${ }^{4}$

Summary: The aim of this study is to report our 3years experience with the screening of congenital disorders of glycosylation. A common isoelectric focusing method with immunofixation was used for analysis of serum transferrin and $\alpha_{1}$-antitrypsin, apart from several other procedures. A group of about 1000 individuals, both healthy controls and patients, mostly with signs of a metabolic disease were examined. Here we present an overview of 1) hypoglycosylation findings, 2) distribution of protein variants, 3) misguiding rare Tf variants found in our set, and 4) association of some phenotypes with various diseases.

Key words: Glycoproteins; Hypoglycosylation; Inborn errors; Screening; Methods

\section{Introduction}

Glycosylation of proteins and lipids mainly takes place in endoplasmic reticulum and the Golgi apparatus of various cells, primarily of the liver. Congenital disorders of glycosylation (CDG) make a new group of inherited metabolic diseases (IMD) with autosomal recessive pattern of inheritance. Pathogenesis of CDG is a consequence of impaired building or processing of glycoproteins caused by various enzymes or transport defects, thus resulting in hypoglycosylation. Two main types (CDG I and CDG II) and an ever-increasing number of subtypes can be differentiated (CDG type Ia-l and CDG type IIa-d, so far).

CDG affect all organs and particularly the CNS, with the exception of CDG types Ib and Ih, where hepatic-intestinal signs prevail. The most frequent type Ia presents differently in various life periods. Clinical signs are dominated by psychomotor retardation and blood coagulation defects, presenting as thrombosis, bleeding, or stroke-like episodes, but many other symptoms occur, e.g. cerebellar hypoplasia, ophthalmologic abnormalities, dysmorphic features, and neuropathy. The CDG type II is rare, but usually has a more severe clinical course compared to CDG type I $(9,11,20)$.

Various screening methods are available, the most common one being isoelectric focusing (IEF) of serum transferrin (Tf), apart from other procedures (combined commercial chromatographic assays, capillary- or agarose gel electrophoresis, or HPLC), and other glycoproteins, e.g. thyroxin-binding globulin (TBG) and antithrombin III (AT III), suitable for the first step of diagnostics. However, this approach cannot identify all defects, so that other investigations, such as thorough analysis of glycans, and especially enzyme assays and mutations identification must follow.

The aim of our effort was to introduce a screening procedure for this recently recognized group of inherited metabolic disorders, in our country not diagnosed before. Here we present results of our 3-years experience, involving only one, rather small region of Czech Republic.

\section{Materials and methods}

About 1000 serum samples of both healthy controls $(n=100$; blood donors, surgery-patients, friends, and relatives) and patients with various clinical, mostly IMD-suspicious symptoms of various ages ( 1 months -62 years) were screened. Serum of premature newborns, alcohol abusers and patients with hepatopathy served as pathological reference samples (due to secondary defects of glycosylation as consequence). Also CDG-positive samples obtained from other laboratories have been checked out. Only surplus material was used for analyses.

Besides serum and plasma, also dry spots with blood or other type of material are suitable for analysis: $4 \mathrm{~mm}$ circle was punched out and eluted with $60 \mu \mathrm{l}$ distilled water for $24 \mathrm{~h}$ at $+4{ }^{\circ} \mathrm{C}$, and about $40 \mu \mathrm{l}$ of the eluate was removed, after centrifugation ready for IEF (29). Cerebrospinal fluid (CSF) was either concentrated (15-times in vacuum) and 
further processed in the same way as the serum, or a native sample was used, and finally stained with more sensitive silver nitrate (see later) because of comparatively lower levels of Tf in this material. Urine is suitable for analysis of oligosaccharides, useful in CDG type IIb diagnosis.

All chemicals were of analytical grade, supplied by Pharmacia, Merck, Sigma, or Bio-Rad. Use of double-distilled water for all analytical steps is essential.

Tf isoforms by IEF. IEF of $\mathrm{Tf}$ is a simple and rapid technique, which allows quantitative determination of all the $\mathrm{Tf}$ isoforms. Tf is a glycosylated iron-transporting protein, synthesized mainly by the liver. Serum Tf generally occurs in sialylated form: five sialic acid residues contribute to the acidic pI of Tf, and their loss causes a basic shift within the $\mathrm{pI}$ of 5.2-5.9. Current methods use IEF combined either by Western blotting, or immunofixation with Coomassie Brilliant Blue/silver nitrate staining. The latter variant, which was employed in our study is basically that used in Nijmegen laboratories (see Acknowledgment) (23) with minor modifications. For comparison of results, other procedures have also been tested.

Iron saturation of Tf. Serum Tf has two iron-binding sites, but normally only about one-third of $\mathrm{Tf}$ is fully saturated. Differences in the ferrous ion content lead to different IEF pattern, and thus in vitro iron saturation is generally necessary. It is achieved by mixing $50 \mu \mathrm{l}$ serum (dry-spot eluate or other material) with $15 \mu$ freshly prepared mixture of ferric citrate $(10 \mathrm{mmol} / \mathrm{l})$ and $\mathrm{NaHCO}_{3}(0.5 \mathrm{~mol} / \mathrm{l}), 2: 1$. After $1 \mathrm{~h}$ incubation at room temperature, the samples (except the concentrated CSF) were diluted 6-times with water, thus ready for application $(6,16)$.

Gel hydration. Dry IEF gels with immobilized $\mathrm{pH}$ gradient, ranging from $\mathrm{pH}$ 4.0-7.0 (Immobiline DryPlate, $240 \mathrm{x}$ $110 \times 0.5 \mathrm{~mm}$, Pharmacia) were rehydrated (in vertical position of cassette with U-frame, previously touched with Repel-Silane, Pharmacia) in glycerol ( $2.2 \mathrm{~mol} / 1$, about 25 $\mathrm{ml})$ for $2 \mathrm{~h}$ at room temperature. The gel can be then stored up to one week at $+4{ }^{\circ} \mathrm{C}(12)$.

IEF separation. LKB Multiphor 2217 and Power Supply 2103 was used. After the rehydrated gel was installed (by use of paraffin oil drops, without air-bubbles) on the cooling plate, both cathodal and anodal electrode strips, soaked with ampholine solutions $\mathrm{pH}$ 6.0-8.0 and 3.5-5.0, resp. (codes 80-1125-93 and 80-1125-89, Amersham), were placed on the appropriate gel margins. The gel was then pre-focused for $10 \mathrm{~min}$ at $1000 \mathrm{~V}, 4 \mathrm{~mA}, 4$ watt, and then for $20 \mathrm{~min}$ at $2000 \mathrm{~V}, 4 \mathrm{~mA}, 8$ watt. After $1.5 \mu \mathrm{l}$ of saturated serum/plasma sample (or $3 \mu \mathrm{CSF}$, and $5 \mu 1$ of a dryspot eluate) were applied to the gel, IEF continues for 30 min at $1000 \mathrm{~V}, 4 \mathrm{~mA}, 4$ watt, and finally for $4 \mathrm{~h}$ at 2000, 4 $\mathrm{mA}, 8$ watt, constantly at $+10{ }^{\circ} \mathrm{C}$.

Immunofixation. Immediately after IEF, the gels were covered with $900 \mu \mathrm{l}$ of polyclonal IgG antibodies to $\mathrm{Tf}$ (Dako, code A 0061), and incubated in a moist chamber for 45 min. Unprecipitated (non-Tf) proteins were overnight washed out from the gel by saline. Next day the gel was kept in distilled water for $1 \mathrm{~h}$ by reason of salts elimination, and Tf isoforms were then fixed to the gel by trichloracetic acid (20 g/100 ml, 10 min washing).

Staining. Gel was stained for $10 \mathrm{~min}$ by continuous shaking in freshly prepared mixture of Coomassie Blue stock solution (Pharmacia, prepared according to producer instructions), and acetic acid (3,6 mol/1), 1:1. Alternatively, a silver nitrate was used for low Tf levels in CSF (26). Destaining was done with a mixture of methanol-acetic acid-water, 3:1:6, until colorless background. The gel was then dried by air, and evaluated by densitometry (DS2D, $\mu \mathrm{LaAp}, \mathrm{SR}$, with MS ScanSlide and ICR software).

Interpretation. IEF in a $\mathrm{pH}$ gradient of 4.0-7.0 reveals eight $\mathrm{Tf}$ isoforms: the tetra- and pentasialo-Tf prevail in healthy controls, while the CDG patient's serum shows a marked elevation of hyposialylated forms (such as disialo-, monosialo-, and asialo-Tf, called carbohydrate deficient Tf, CDT). IEF CDG type I pattern shows decreased tetrasialoTf and a marked elevation of disialo-Tf, while the asialo-, monosialo-, and disialo-Tf typically increase in CDG type IIa and IId, although the both patterns may diverge $(9,15,20)$.

Detection of polymorphism in Tf glycoprotein. An extended polymorphism of TF is well known, some of the variants being difficult to distinguish from a CDG pattern, so that a special attention must be paid to their recognition and differentiation. Most common $\mathrm{C}$ (with $\mathrm{C} 1-\mathrm{C} 16$ subtypes), and several subtypes of the rare B and D (both shifting, compared to $\mathrm{C}$ ) variants are distinguished $(1,9)$.

Neuraminidase (sialidase; EC.3.2.1.18) is an enzyme that selectively splits the terminal sialic acid residues on the glycan chain, thus converting all Tf isoforms to the asialoform. Serum of controls at IEF shows one band only, in contrast to protein variants, which retain their shifted or double-banded positions. The freeze-dried powder of enzyme (Sigma, code N-2876) was dissolved $(1 \mathrm{mg} / \mathrm{ml})$ in Tris - $\mathrm{HCl}$ buffer $\mathrm{pH} 7$ (0.1 mol/l), and incubated with iron-saturated serum in a ratio $2: 1$ at room temperature overnight $(16,33)$. A control sample with saline was prepared for comparison. After a 40-time dilution with saline, the 4- $\mu$ l volume was ready for IEF application.

For better interpretation of Tf D (possibly also Tf B) variant, gel of higher $\mathrm{pH}$ range (3.5 -9.0) is used (18), while gel $\mathrm{pH} 5-6$ is more suitable for precise discrimination of $\mathrm{Tf}$ C subtypes (8).

It is widely recommended to confirm generalized defect of glycosylation by analysis of more than just one glycoprotein.

IEF of thyroxin-binding globulin (TBG). The TBG type $\mathrm{C}$ (common) physiologically exhibits mainly the octasialoisoform. The CDG patients show an increase of hyposialylated tetra- and pentasialo-TBG. Our experience with the method $(19,28)$ is limited, as the TBG antibody for immunodetection is commercially no more (hoping temporally) available.

IEF of $\alpha_{1}$-antitrypsin (aAT). The optimum for the most common variant aAT M (86-99\%) lies between $\mathrm{pH} 4-5$, 
nevertheless for practical reasons we tested at first the conditions similar to those used for $\mathrm{Tf}$ (gels of $\mathrm{pH}$ range 4-7). Sample pretreatment with cystein (to prevent anomalous patterns resulting from aged sera) (12), use of specific antibody (anti-aAT, Dako, code Q 0363), and skipping the ironsaturation step, are the minor variation of the method used for $\mathrm{Tf}$ analysis. The hexasialo-isoform is prominent in the healthy, whereas higher tetrasialo-aAT is pathognomic for CDG. The rare $S, Z$, and $F$ genetic variants should be properly identified for reliable interpretation of results (28).

Other screening methods have been checked for comparison of result reliability and economic criteria.

Tf isoforms by electrophoresis on agarose with Western blotting. Proteins are separated by electrophoresis on agarose and then passively transferred onto a nitrocellulose membrane. The immobilized isoforms of $\mathrm{Tf}$ are detected immunochemically using a double antibody system, consisting of rabbit anti-human Tf, followed by HRP-conjugated donkey anti-rabbit serum (15).

Gels were prepared from medium-osmotic agarose and electrophoresis veronal buffer $\mathrm{pH} 8.6, \mathrm{I}=0.085$ ( $1 \mathrm{~g}$ agarose $100 \mathrm{ml}$, dissolved by heating for $15 \mathrm{~min}$ ), placed on a plastic supporter (Pharmacia), and dried with filter paper. Then $2-\mu 1$ volume of serum samples, diluted 50 -times with saline were applied, and electrophoresis was carried-out (LKB Multiphor) at $100 \mathrm{~mA}$ and $400 \mathrm{~V}$ for 4 hours. The gel was dried with filter paper, and the separated proteins were blotted on nitrocellulose sheet (Pharmacia), using a $1 \mathrm{~kg}$ weight-press for $2 \mathrm{~h}$. Two antibodies, namely rabbit antihuman Tf serum (Dako), and donkey anti-rabbit HRP (Amersham), as well as 4-chloro-1-naphthol as a color developer, were used. For other details of Western blotting see $(2,27)$.

Sometimes it is helpful to purify $\mathrm{Tf}$ from serum prior to carrying out further studies (e.g. HPLC), although this is not essential for routine IEF testing; methodical details on Tf pretreatment by affinity chromatography and HPLC will be described elsewhere.

Enzyme assays. Diagnosis of the most frequent type CDG Ia is completed by measurement of cellular phosphomannomutase (PMM; EC 5.4.2.8) activity; the enzyme converts mannose-6-phosphate to mannose-1-phosphate. Similar enzyme assay for checking phosphomannoisomerase (PMI; EC.5.3.1.8) activity is required for CDG type $\mathrm{Ib}$ diagnosis.

Blood samples were obtained from 12 healthy individuals, age range $3 \mathrm{~m}-60 \mathrm{y}$. A two-step procedure has been adopted for isolation of peripheral blood leukocytes: it starts with the heating of whole EDTA-blood $(6-10 \mathrm{ml}$, $37^{\circ} \mathrm{C}, 40 \mathrm{~min}$ ) and centrifuging the separated supernatant. The pellet was then washed by $\mathrm{NaCl}$ solutions in a stepwise manner, using concentrations $0.2,3.6$, and $0.9 / 100 \mathrm{ml}$ with centrifugation in between (5). The cells disintegration was achieved mechanically by numerous passing (30-times) of leukocyte pellets, previously dissolved in $50 \mu \mathrm{l}$ HEPES buffer $\mathrm{pH} 7.1,0.05 \mathrm{~mol} / \mathrm{l}$, through a syringe needle (Luer, $0.5 \times 25)(3)$, one freeze/thaw cycle, and finally, centrifugation at $500 \mathrm{~g}$ for $10 \mathrm{~min}$. The resulting extract was ready for the enzymatic assay and protein determination.

The traditional assay for both enzymes is based on the reduction of NADP $(+)$ to NADPH. A method of van Schaftingen (30) with slight modification (7) was used for both enzyme assays. EDTA-plasma is preferred, giving statistically higher results, when compared to the samples with heparin (3). A volume of the cell supernatant, containing 0.8 $\mathrm{mg}$ of protein $(100-150 \mu \mathrm{l})$ was used; the incubates $(1 \mathrm{ml})$ comprise glucose-1,6-biphosphate (22) instead of the originally recommended mannose-1,6-biphosphate. To detect enzyme activity, spectrophotometer Unicam UV 2, and for protein quantification, Cobas Mira were used.

\section{Results}

The reference values of $\mathrm{Tf}$ isoforms distribution in our set of controls have been established (Table 1).

Abnormalities of glycosylation, detected in about $6.7 \%$ of our patients group have been associated with e.g. Hashimoto thyroiditis, Budd-Chiarri syndrome, systemic lupus erythematosus, and epilepsy (in two infants, treated with Phenaemaletten), apart from liver disease, rheumatoid arthritis, and some patients with cystic fibrosis. No correlation with total serum levels of $\mathrm{Tf}$ and aAT was found.

Tab. 1: Tf isoforms by IEF in controls and various patients showing increased CDT (the values exceeding a reference range are in italics). Distribution in \%; Tf isoforms 0-7: asialo- - heptasialo-Tf; V: our CDG patient, N: C1/D4-5 Tf variant, S: hepatitis $\mathrm{C}, \mathrm{K}$ : lupus erythematosus, $\mathrm{H}$ : antiepileptics in therapy, B: newborn.

\begin{tabular}{|c|c|c|c|c|c|c|c|c|c|}
\hline \multirow{2}{*}{ Tf isoforms } & \multicolumn{2}{|c|}{$\begin{array}{c}\text { Controls } \\
\end{array}$} & \multicolumn{7}{|c|}{ Patients } \\
\hline & Mean & SD & CDG Ia & $\mathbf{V}$ & $\mathbf{N}$ & $\mathbf{S}$ & $\mathbf{K}$ & $\mathbf{H}$ & B \\
\hline $\mathbf{0}$ & 0.4 & 0.4 & 12.4 & 1.9 & 11.7 & 3.3 & 0.0 & 2.7 & 1.8 \\
\hline 1 & 1.3 & 0.9 & 2.4 & 0.0 & 4.5 & 3.7 & 4.4 & 0.0 & 5.4 \\
\hline 2 & 6.5 & 2.2 & 28.5 & 19.2 & 4.9 & 12.0 & 7.6 & 3.6 & 9.2 \\
\hline 3 & 13.2 & 7.3 & 8.8 & 8.7 & 2.0 & 19.8 & 10.3 & 12.2 & 9.4 \\
\hline 4 & 51.2 & 11.0 & 39.8 & 51.0 & 60.4 & 40.0 & 50.8 & 44.7 & 59.1 \\
\hline 5 & 18.8 & 8.1 & 8.1 & 11.5 & 6.3 & 12.5 & 15.1 & 24.8 & 9.5 \\
\hline 6 & 6.3 & 3.4 & 0 & 7.8 & 7.2 & 7.7 & 7.0 & 9.2 & 5.6 \\
\hline 7 & 2.3 & 2.5 & 0 & 0 & 3.0 & 1.0 & 4.6 & 2.8 & 0 \\
\hline
\end{tabular}




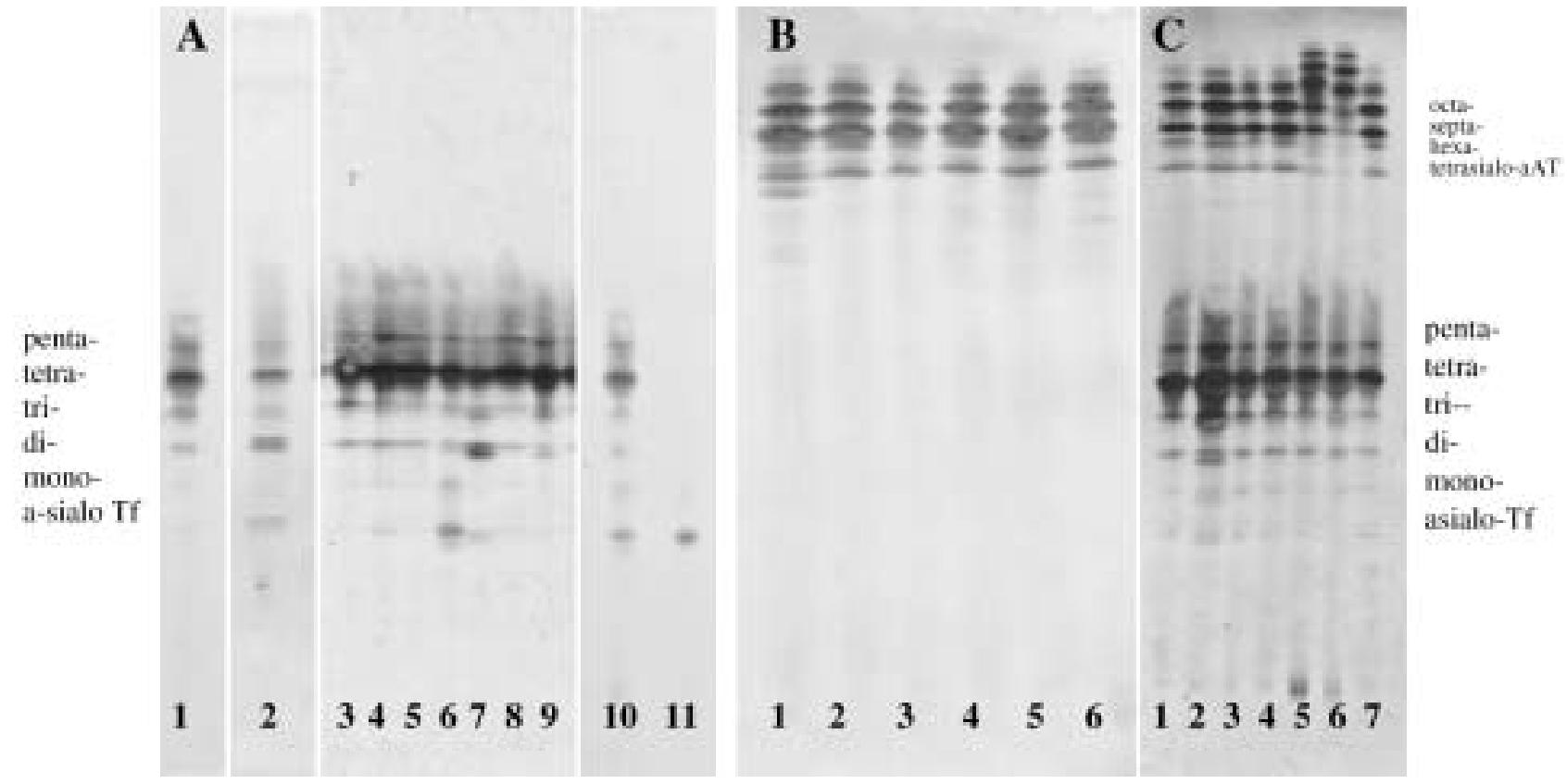

Fig. 1: IEF of Tf and aAT on Immobiline DryPlate gel at $\mathrm{pH}$ range 4-7.

A) Tf: Lane 1, 3, 4, 5, 8, 9: healthy controls, Lane 2: a CDG type Ia patient (Tf C1/C2), Lane 6: Tf C1/D4-5 variant, Lane 10: the same variant in the father, Lane 11: as in the Lane 10 after neuraminidase treatment, Lane 7: our CDG patient (Tf $\mathrm{C} 1 / \mathrm{C} 2$ ); note increase disialo-Tf when compared to controls.

B) aAT: Lane 1: our CDG patient, Lane 2, 3: father and mother of the CDG patient, Lane 4, 5, 6: healthy controls; note the extra band of our CDG patient when compared to the controls.

C) Tf and aAT on the same gel, Lane 1, 3, 4, 7: healthy controls, Lane 2: secondary increase CDT (Tf C1/C2), while aAT is normal, Lane 5, 6: normal Tf, but aAT polymorphism.

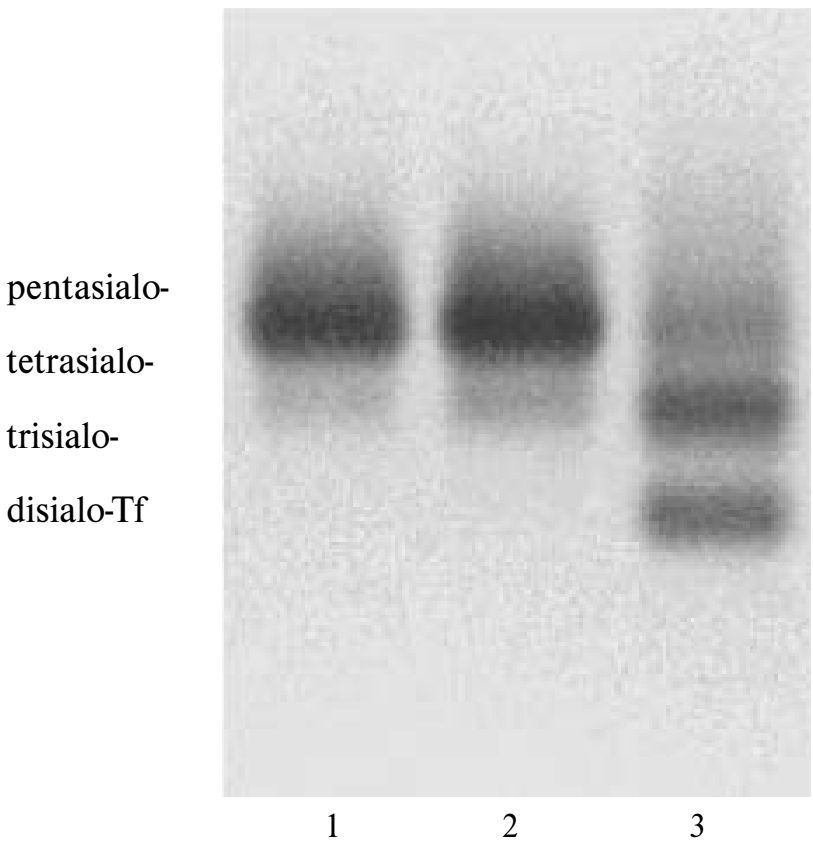

Fig. 2: Agarose electrophoresis pattern of Tf isoforms; Lanes 1, 2: controls, Lane 3: patient with CDG type Ia.
The clinical feature of a 5-year-old mentally retarded boy with various nonspecific symptoms raised suspicion of CDG. IEF showed an increase of disialo-Tf (Table 1) compared with normal mean values. Also aAT analysis revealed abnormal IEF-profile in this child (Fig. 1), as well as a result of electrophoretic separation of $\mathrm{Tf}$ isoforms on agarose gel (Fig. 2). The patient is a carrier of the $\mathrm{C} 1 / \mathrm{C} 2$ (double bands) genetic variant. Further analysis of serum TF disclosed that this TF variant was inherited from patient's mother, otherwise healthy. PMM assay showed only slight decrease of enzyme activity in leukocytes; mutation analysis is pending.

In our set of subjects besides the most common $\mathrm{C} 1-\mathrm{Tf}$ variant ( $84 \%$ in controls and $79 \%$ in the patient group), we have found also the heterozygous $\mathrm{C} 1 / \mathrm{C} 2$ form with a significantly higher frequency in the Crohn's disease (30\%) and the cystic fibrosis $(27 \%)$ patient subgroups, compared to controls (16\%) and the total patients group (20\%). Other rare phenotypes $\mathrm{C} 2, \mathrm{C} 1 / \mathrm{C} 3, \mathrm{C} 1 / \mathrm{B}$ and $\mathrm{C} 1 / \mathrm{D}$ (in $0.48,0.32$, 0.24 and $0.24 \%$, resp.), were also recognized (Albahri, in press).

To demonstrate a risk of the possible misinterpretation we report on a methotrexate treated adolescent boy, followed for potential long-therapy-effects on the Tf-glycoforms 
ratio. His IEF pattern showed isolated increase of asialo-Tf (Fig. 1). Further investigation based on the neuraminidase test, analysis of serum aAT, and a search for a polymorphism type in the family confirmed the suspected rare C1/D4-5 genetic variant, thus falsely simulating a CDG.

No gender differences from the viewpoint of both aspects, hypoglycosylation and distribution of genetic variants, have been found in our set of patients and controls.

Possibility of simultaneous analysis of Tf and aAT in the same gel was tested with good results; as the position of individual isoforms doesn't overlap, both specific antibody solutions can be applied on the appropriate parts of gel surface for selective detection. Having been inspired by Artuch et al (2), we used also an antibody cocktail for detection of both glycoproteins in one run (Fig. 1).

\section{Discussion}

Screening of serum Tf by IEF proved to be reliable at the first stage of CDG diagnostics. IEF conditions similar to those described for Tf are also suitable for aAT analysis, so that glycosylation level of both glycoproteins, greatly significant for CDG diagnostics, may be followed by one IEF run.

The IEF screening of CDG is unreliable in neonates in the first 3 weeks of life, when a significant proportion of circulating Tf is still derived from the mother source.

Some other conditions should be first excluded from the possible differentials before a diagnosis of CDG is made, such as pregnancy, galactosemia, fructosuria, alcohol abuse, severe liver diseases, chronic obstructive lung disease, irondeficient anemia, and possibly the use of antiepileptic medication.

Also changes in the amino acid sequence of the polypeptide chain of $\mathrm{Tf}$ (namely the $\mathrm{D}$ genetic variants) should be always considered; test with neuraminidase gives an unambiguous result. The knowledge of Tf microheterogeneity is fundamental for correct analysis and interpretation of IEF results; at least $36 \mathrm{Tf}$ protein variants are known, showing a distinct variability.

The distribution and frequency of genetic variants in our set roughly correspond to those reported for the European population (homozygous variant $\mathrm{C}$ in $98 \%$, B and D are rare; subtypes: $\mathrm{C} 1$ in $70-80 \%, \mathrm{C} 2-\mathrm{C} 16$ in $2 \%$; heterozygous variants: $\mathrm{C} 1 / \mathrm{C} 2$ in $10 \%, \mathrm{C} 1 / \mathrm{C} 3$ and $\mathrm{B} / \mathrm{C}$ in $0.7 \%$, and $\mathrm{C} / \mathrm{D}$ in $0.2 \%$ ) (13).

An association of certain genetic diseases with some pathological conditions was reported, e.g. higher frequency of $\mathrm{Tf} \mathrm{C} 2$ variant with spontaneous abortion, prematurity, rheumatoid arthritis (25), Alzheimer's disease (21), and lower Fe-binding capacity (31). Tf C3 is suggested to show certain protection against some smoking-derived types of lung-carcinoma (4). On the other hand, comparably lower occurrence of $\mathrm{Tf} \mathrm{C} 1 / \mathrm{C} 2$ is reported in patients with cystic fibrosis (24). Our finding of increased frequency of the heterozygous $\mathrm{C} 1 / \mathrm{C} 2$ variant in children rather contradicts (cystic fibrosis) and further extends (Crohn's disease) these observations.

The algorithm of $C D G$ investigation begins with physician's suspicion, based on clinical symptoms and/or biochemical findings (low level of various serum glycoproteins). CDG screening usually starts with IEF of serum Tf isoforms, but other methods (17), and also other glycoproteins, such as aAT, TBG, AT III, $\alpha_{1}$-antichymotrypsin, ferritin, $\alpha_{2}$-antiplasmin, haptoglobin, orosomucoid, vitamin D-binding protein, retinal-binding protein, $\alpha_{2}$-HS-glycoprotein (fetuin), plasminogen, or $\mathrm{Zn}-\alpha_{2}$-glycoprotein $(28,34)$ and hexosaminidase (10) are convenient for CDG screening. However, possible protein polymorphism must always be considered.

When excluding all possible secondary causes (young age, severe liver afflictions, galactosemia and fructosuria, or rare Tf variants), positive IEF results usually reliably lead to diagnosis of CDG type I, which is further proved by enzyme assays and mutation analysis.

However, negative IEF result doesn't exclude rarer CDG types IIb and IIc, so that the structure of either lipidlinked or protein-linked glycan, possibly membrane antigens (such as Bombay, or Lewis-X) in leukocytes, or lectin binding ability, should be followed. Glycophorin A and the band III in erythrocyte membrane may be pathognomic for HEMPAS and CDG type Ig, resp., and some other subtypes, not clearly classified so far (CDG-x) (20).

Moreover, electrophoretic analysis of serum apolipoproteins C-III and apo-E (32), as well as $\alpha$-dystroglycan in skeletal muscle (14) may be helpful for detection of O-glycosylation defects, which possibly constitute a new CDG subgroup.

Since CDG is an autosomal recessive congenital disorder, it has important consequences for the family, and thus a genetic counseling should be offered.

The disease probably remains largely underdiagnosed. Following the frequent reports on diversity of clinical signs in CDG patients, the screening criteria should be very wide. Thus the CDG diagnosis is to be considered in all cases with psychomotor retardation, ophthalmologic abnormalities, seizures, multiorgan failure, and liver and clotting abnormalities, at least.

\section{Acknowledgment}

Thanks are due to K. Huyben, Univ. Klinisch-Genetisch Centrum, Nijmegen, Netherlands, to G. Keir, Department of Neuroimmunology, National Hospital for Neurology and Neurosurgery, London, UK and to J Pribišová, Fac Hosp, Hradec Králové, CR for advice and laboratory manuals.

The study was supported by Grant No 85/2001/C/ LFHK and partly by Grant No 1770/G3/FRVS from Charles University, Czech Republic.

\section{References}

1. Arndt T. Carbohydrate-deficient transferrin as a marker of chronic alcohol abuse: a critical review of preanalysis, analysis, and interpretation. Clin Chem 2001; 47(1):13-27. 
2. Artuch R, Ferrer I, Pineda J et al. Western blotting with diaminobenzidine detection for the diagnosis of congenital disorders of glycosylation. J Neurosci Methods 2003;125:167-71.

3. Barnier A, Dupré T, Cuer M, Vuillaumier-Barrot S, Durand G, Seta N. Leukocyte phosphomannomutase activity in diagnosis of congenital disorder of glycosylation Ia. Clin Chem 2002;48:934-6.

4. Beckman LE, Van Landeghem GF, Sikstrom C, Lundgren R, Beckman L. Protective effect of transferrin C3 in lung cancer? Oncology 1999;56(4):328-31.

5. Beutler E, Kuhl W. The diagnosis of the adult type of Gaucher's disease and its carrier state by demonstration of deficiency of beta-glucosidase activity in peripheral blood leukocytes. J Lab Clin Med 1970;76:747-55.

6. de Jong G, van Noort WL, Feelders RA, de Jeu-Jaspars CM, van Eijk HG. Adaptation of transferrin protein and glycan synthesis. Clin Chim Acta 1992 212(1-2):27-45

7. de Koning TJ, Dorland L, van Diggelen OP et al. A novel disorder of N-glycosylation due to phosphomannose isomerase deficiency. Biochem Biophys Res Commun 1998;245(1):38-42.

8. Gorg A, Weser J, Westermeier R et al. Isoelectric focusing with immobilized $\mathrm{pH}$ gradients for the analysis of transferrin (Tf) subtypes and variants. Hum Genet 1983; 64(3):222-6

9. Grünewald S, Matthijs G, Jaeken J. Congenital disorders of glycosylation: a review. Pediatr Res 2002;52:618-24.

10. Jaeken J, Kint J, Spaapen L. Serum lysosomal enzyme abnormalities in galactosaemia. Lancet 1992;340(8833):1472-3.

11. Jaeken J. Komrower Lecture. Congenital disorders of glycosylation (CDG): it's all in it! J Inherit Metab Dis 2003;26:99-118.

12. Jeppsson JO, Franzen B. Typing of genetic variants of alpha 1-antitrypsin by electrofocusing. Clin Chem 1982;28(1):219-25.

13. Kamboh MI, Ferrell RE. Human transferrin polymorphism (review). Hum Hered $1987 ; 37: 65-81$

14. Kano H, Kobayashi K, Herrmann R et al. Deficiency of a-dystroglycan in muscleeye-brain disease. Biochem Biophys Res Commun 2002;291:1283-86.

15. Keir G, Winchester BG, Clayton P. Carbohydrate-deficient glycoprotein syndromes: inborn errors of protein glycosylation. Ann Clin Biochem 1999:36:20-36.

16. Kim S, Westphal V, Srikrishna G et al. Dolichol phosphate mannose synthase (DPM1) mutations define congenital disorder of glycosylation Ie (CDG-Ie) J Clin Invest 2000;105(2):191-8

17. Kleinert P, Kuster T, Durka $S$ et al. Mass spectrometric analysis of human transferrin in different body fluids. Clin Chem Lab Med 2003:41(12):1580-8.

18. Kühnl P, Spielmann W. A third common allele in the transferrin system, TfC3, detected by isoelectric focusing. Hum Genet 1979;50(2):193-8.

19. Macchia PE, Harrison HH, Scherberg NH, Sunthornthepfvarakul T, Jaeken J, Refetoff S. Thyroid function tests and characterization of thyroxine-binding globulin in the carbohydrate-deficient glycoprotein syndrome type I. J Clin Endocrinol Metab 1995;80:3744-9.

20. Marquardt T, Denecke J. Congenital disorders of glycosylation: review of their molecular bases, clinical presentations and specific therapies. Eur J Pediatr 2003; 162:359-79.

21. Namekata K, Imagawa M, Terashi A, Ohta S, Oyama F, Ihara Y. Association of transferrin C2 allele with late-onset Alzheimer's disease. Hum Genet 1997 101(2):126-9.
22. Niehues R, Hasilik M, Alton G et al. Carbohydrate-deficient glycoprotein syndrome type $\mathrm{Ib}$. Phosphomannose isomerase deficiency and mannose therapy. J Clin Invest 1998:101:1414-20.

23. Noort WL van, Jong G de, Eijk HG van. Ideale scheidingen kwantificering van sialo transferrinefracties in humaan serum. Tijdschr NVKC 1993;18:43-45.

24. Pascali VL, Bravo E, Auconi $\mathrm{P}$ et al. Transferrin subtypes in cystic fibrosis. Eur J Pediatr 1984;143(2):133-4

25. Petrén S, Vesterberg O. Separation of different forms of transferrin by isoelectric focusing to detect effects on the liver caused by xenobiotics. Electrophoresi 1989;10(8-9):600-4.

26. Roelandse FWC, van der Zwart N, Didden JH, van Loon J, Souverijn JHM. Detection of CSF leakage by isoelectric focusing on polyacrylamide gel, direct immunofixation of transferrins, and silver staining. Clin Chem 1998;44:351-3.

27. Seta N, Barnier A, Hochedes F, Besnard MA, Durand G. Diagnostic value of Western blotting in carbohydrate deficient glycoprotein syndrome. Clin Chim Acta 1996;254:131-40.

28. Stibler H, Holzpach U, Kristiansson B. Isoforms and levels of transferrin, antithrombin, $\alpha_{1}$-antitrypsin and thyroxine-binding globulin in 48 patients with carbohydrate-deficient glycoprotein syndrome type I. Scand J Clin Lab Invest 1998 58:55-62.

29. Stibler H, Jaeken J, Kristiansson B. Biochemical characteristics and diagnosis of the carbohydrate-deficient glycoprotein syndrome. Acta Paediatr Scand 1991;375 (Suppl 375):21-31

30. Van Schaftingen E, Jaeken J. Phosphomannomutase deficiency is a cause of carbohydrate-deficient glycoprotein syndrome type I. FEBS Lett 1995;377:318-20.

31. Wong CT, Saha N. Effects of transferrin genetic phenotypes on total iron-binding capacity. Acta Haematol 1986;75(4):215-8.

32. Wopereis S, Grünewald S, Morava E et al. Apolipoprotein C-III Isofocusing in the diagnosis of genetic defects in O-glycan biosynthesis. Clin Chem 2003; 49:1839-45.

33. Wuyts B, Delanghe J R, Kasvosve I. Determination of carbohydrate-deficien transferrin using capillary zone electrophoresis. Clin Chim 2001;47:247-255.

34. Yuasa I, Ohno K, Hashimoto K, Iijima K, Yamashita K, Takeshita K. Carbohydrate deficient glycoprotein syndrome: electrophoretic study of multiple serum glycoproteins. Brain Dev 1995;17:13-9.

Submitted March 2004

Accepted July 2004.

MUDr. Eliška Marklová, Ph.D., Charles University in Prague, Department of Pediatrics, Laboratory of Inherited Metabolic Diseases, 50005 Hradec Králové, Czech Republic. e-mail: marklova@lfhk.cuni.cz 